\title{
Erratum
}

Jürg Hulliger*, Thomas Wüst, and Mathias Rech

\section{Symmetry and the polar state of condensed molecular matter}

*Correspondence Author: Jürg Hulliger, GeoBioCenterLMU and Department of Chemistry and Biochemistry, University of Berne, Freiestr. 3, 3012 Bern, Switzerland,

e-mail: juerg.hulliger@iac.unibe.ch

Thomas Wüst, Mathias Rech: GeoBioCenterLMU and Department of Chemistry and Biochemistry, University of Berne, Freiestr. 3, 3012 Bern, Switzerland
In the above mentioned paper some errors should be corrected:

1) Page 1, paragraph 4, line 9: replace $\infty / \mathrm{m}$ by $\infty$

2) Page 2, paragraph 2, line 6: replace $(\infty / \mathrm{m})^{2}$ by $(\infty \mathrm{m})$

3) In the graphical abstract line 6: replace $1800^{\circ}$ by $180^{\circ}$ 